$\left(\alpha-\mathrm{SiO}_{2}\right)$ とロドナイト，( $\left.\mathrm{MnO} \cdot \mathrm{SiO}_{2}\right)$ の共存状態より なる珪酸塩系介在物と，MnS と FeS の共存状態ある いは MnS 単独状態よりなる硫化物系介在物との 2 つ の柔統に大別された. したがつて珪酸塩介在物の組成は $\mathrm{SiO}_{2}-\mathrm{MnO}$ 采中の $\mathrm{SiO}_{2}$ と $\mathrm{MnO} \cdot \mathrm{SiO}_{2}$ の共存範囲に ありまた硫化物系介在物のそれは-MnS-FeS 系中の $\mathrm{MnS}$ と FeS の共存範囲あるいは MnS 範囲にあるる のと考えられる. 以上の非金属介在物の他に，他の組成 の化合物からなる介在物および電子回折によつては同定 できなかつた介在物がわずかではあるが存在した。

終りに郜み本研究の発表を許可された大河原社套, い ろいろと御教示を賜つた村上先生, 玉置前研究部長，佐

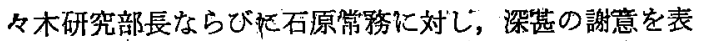
するとともに，分析その他でお世話になつた森脇次長， 松本課員そ.の他の関係各位に御礼申し上げる.

\section{文” . 献}

1) R. M. Fisher; Symposium on Techniqu for Electron Microscope, A.S.T.M., (1953 49

2) 获川，内山，深見；鉄と鋼，43（1957） 1222

3) G. R. Booker,; British J. Appl. Phys., 6 (1955) 430

4) Metals Hand Book, A.S.M., ' (1954) 449

5) A. M. "Portevin \& R. Castro,; J. Iron and Steel Inst., 2 (1936) 21,3

6) J. H. Whiteley; J. Iron and Steel Inst., 160 (1948) 365

7) J. Amer.' Ceram. Sóc., 21 (1938) 121

8) R. Vogel u. W. Hotop; Arch. Eisenhütt., 1 (1.937) 41

(昭和 34 年 2 月奇稿)

\title{
実用 $\mathrm{Ni}$ 基酎熱合金の機械的性質の比較 ${ }^{*}$
}

（Ni 基耐熱合金に関する研究一V)

\section{長 谷川太 郎** \\ Comparison of Mechanical Properties at Elevated Temperature of Some Commercial Ni-base Heat-Resisting Alloys.}

\author{
(Studies on Ni-base heat-resisting alloys-V)
}

\section{Taro Hasegawa}

Synopsis:

Mechanical properties at elevated temperature of six commercial Ni-base heat-resisting alloys were investigated, and the effects of $\mathrm{Co}$, Mo and $\mathrm{Nb}$ on mechanical properties were compared.

When compared the mechanical properties of $\mathrm{Ni}-\mathrm{Cr}$ were with $\mathrm{Ni}-\mathrm{Cr}$-Co alloys, Co was found to be effective to increase strength at high temperature and long time test, and it also increased ductility at room \& elevated temperature.

Mo was found to be effective to increase strength at high -temperature, but it gave effect to decrease at high and long time test. M252 which contained 10\% of Mo was found to have a lower creep rupture strength above $750^{\circ} \mathrm{C}$ than Inco 700 which contained lower Mo, but higher Ti, Al and Co. But M252 had the highest creep ductility at high temperature.

$\mathrm{Nb}$ was found to be effective to increase high-temperature strength as well as $\mathrm{Ti} \& \mathrm{Al}$. But its effect was not clear in short time test of tensile strength. Therefore, Inconel X-550 had the highest stress rupture strength among $\mathrm{Ni}-\mathrm{Cr}$ alloys. Creep ductility was decreased remarkably by the addition of $1.2 \% \mathrm{Nb}$ as $\mathrm{Ni}-\mathrm{Cr}$ alloys which contained high $\mathrm{Ti}$ and $\mathrm{Al}$.

*昭和 33 年 4 月本会講演大会にて発表 ** 住友金属工業 K K製鋼所 


\section{I. 緒言}

前報までに6-種の $\mathrm{Ni}$ 基耐熱合金の機械的性質につい てのべてきたので，本報ではこれらの結果を総合して， 実用成分の合金炕より・Ti，Al，Nb，Mo，Co など添 加元素の機械的性質に抒よぼす影響についてのべたい。

\section{II. 供試材}

すで報告した各合金の中で最も良好な機械的性質を 示した試料をえらび，また熱処理法は各合金について代 表的方法它採用した. Table 1 k!供試材の化学成分を Table 2 におのおの熱処理法を示す．供試材は既竍のご とく真空熔解した $40 \mathrm{~kg}$ 鋳塊を $15 \mathrm{~mm} \phi$ に鉎伸した まのである.

\section{III. 短時間機械的性質}

Fig. 1 亿常温 $700,750,800^{\circ} \mathrm{C}$ の短時間引張試験結 果を示し，Fig. 2 に常温衝撃值定示す。これらの結果を 要約するとつぎのごとくなる.

（1）抗張力，耐力では6 種の合金中 M252 は最む 高く，Inco 700 はこれについでいる.しかるにこれら と同采の Ni-Cr-Co 系合金に属する Nimonic 90 は 上の二者よりかなり低く， Ni-Cr 系の Nimonic 80A とくらべると $700^{\circ} \mathrm{C}$ 以上で高い強度をむつが, Inco 739 と同等加むしろ低い強度となる。すすなわち $\mathrm{Ni}-\mathrm{Cr}$ 系合金㳊 $18 \% \mathrm{Co}$ を添加したのみでは高温強度はや や高くなるが，Moを3\% 添加した場 合と大差ない程 度の奻果である。
(2) $\mathrm{Ni}-\mathrm{Cr}$ 系合金の抗張力, 耐力は Mo-家含 むInco 739 加 最も高い強度を もち. Nimonic $80 \mathrm{~A}$, Inconel $\mathrm{X}-550$ がこれ についでいる. Inconel X-550 は Nbを含んで いるが，強度は むしろ Nimonic $80 \mathrm{~A}$ より低 W.

(3) 伸び， 紋り江各合金共 常温では比較的 大きいが，700， $750^{\circ} \mathrm{C}$ の試験温 度で注高温試験 中の析出硬化の ため低下する.

$\mathrm{Ni}-\mathrm{Cr}$ 系を Ni-Cr-Co 系で はとくに明らか な相違は席く， $\mathrm{Mo}, \mathrm{Nb}$ 安含ま

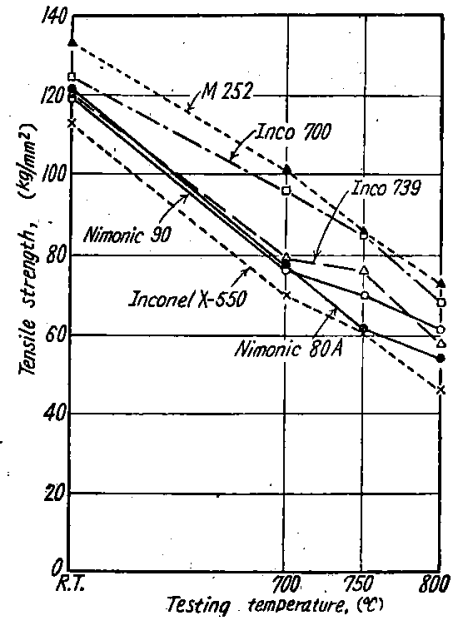

Fig. 1. a) Short-time tensile properties of various Ni-base heat-resisting alloys.

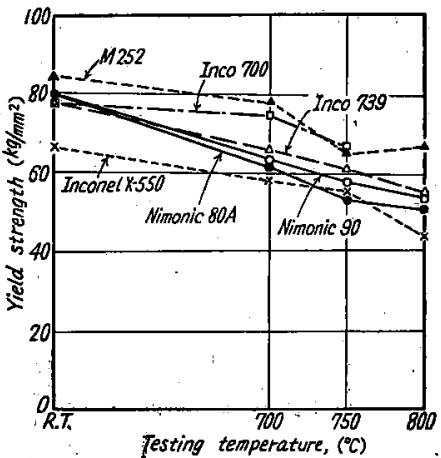

Fig. 1. b) Short-time tensile properties of various $\mathrm{Ni}$-base heat-resisting alloys.

Table 1. Chemical compositions of materials tested.

\begin{tabular}{l|c|c|c|c|c|c|c|c|c|c|c|c|c}
\hline \multicolumn{1}{c|}{ Alloy } & $\begin{array}{c}\text { No. } \\
\text { charge }\end{array}$ & $\mathbf{C}$ & Si & Mn & P & S & Cr & Ni & Co & Mo & Nb+Ta & Ti & Al \\
\hline Nimonic 80A & A52 & $0 \cdot 01$ & $0 \cdot 27$ & $0 \cdot 21$ & $0 \cdot 006$ & $0 \cdot 005$ & $19 \cdot 97$ & $74 \cdot 40$ & $1 \cdot 95$ & - & - & $2 \cdot 37$ & $1 \cdot 22$ \\
Irconiel X-550 & A57 & $0 \cdot 06$ & $0 \cdot 21$ & $0 \cdot 21$ & $0 \cdot 010$ & $0 \cdot 006$ & $15 \cdot 11$ & $78 \cdot 58$ & - & - & $1 \cdot 22$ & $2 \cdot 18$ & $1 \cdot 21$ \\
Inco 739 & A74 & $0 \cdot 07$ & $0 \cdot 04$ & tr & $0 \cdot 016$ & $0 \cdot 004$ & $15 \cdot 16$ & $77 \cdot 25$ & - & $2 \cdot 95$ & - & $1 \cdot 79$ & $2 \cdot 76$ \\
Nimonic 90 & N43 & $0 \cdot 07$ & $0 \cdot 07$ & $0 \cdot 07$ & $0 \cdot 016$ & $0 \cdot 008$ & $20 \cdot 03$ & $59 \cdot 53$ & $16 \cdot 51$ & - & - & $2 \cdot 39$ & $1 \cdot 67$ \\
Inco 700 & N44 & $0 \cdot 11$ & $0 \cdot 07$ & $0 \cdot 11$ & $0 \cdot 011$ & $0 \cdot 007$ & 15.37 & $48 \cdot 4028 \cdot 49$ & $2 \cdot 97$ & - & $2 \cdot 12$ & $3 \cdot 33$ \\
M252 & N21 & $0 \cdot 11$ & $0 \cdot 42$ & $0 \cdot 35$ & $0 \cdot 008$ & $0 \cdot 005$ & $19 \cdot 27$ & $55 \cdot 80$ & $10 \cdot 81$ & $9 \cdot 37$ & - & $2 \cdot 98$ & $0 \cdot 81$ \\
\hline
\end{tabular}

Table 2. Heat treatment of specimens tested.

\begin{tabular}{l|c|c}
\hline \multicolumn{1}{c|}{ Alloy } & $\begin{array}{c}\text { Symbol of heat } \\
\text { treatment }\end{array}$ & Procedures of heat treatment \\
\hline Nimonic 80A & $\mathrm{A}$ & $1065^{\circ} \mathrm{C} \times 8 \mathrm{~h}-\mathrm{AC}, 700^{\circ} \mathrm{C} \times 18 \mathrm{~h}-\mathrm{AC}$ \\
Inconel X-550 & $\mathrm{F}$ & $1180^{\circ} \mathrm{C} \times 1 \mathrm{~h}-\mathrm{AC}, 870^{\circ} \mathrm{C} \times 4 \mathrm{~h}-\mathrm{AC}, 730^{\circ} \mathrm{C} \times 4-\mathrm{AC}$ \\
Inco 739 & $\mathrm{E}$ & $1120^{\circ} \mathrm{C} \times 4 \mathrm{~h}-\mathrm{AC}, 980^{\circ} \mathrm{C} \times 1 \mathrm{~h}-\mathrm{AC}, 730^{\circ} \mathrm{C} \times 4 \mathrm{~h}-\mathrm{AC}$ \\
Nimonic 90 & $\mathrm{~A}$ & $1065^{\circ} \mathrm{C} \times 8 \mathrm{~h}-\mathrm{AC}, 700^{\circ} \mathrm{C} \times 18 \mathrm{~h}-\mathrm{AC}$ \\
Inco 700 & $\mathrm{D}$ & $1180^{\circ} \mathrm{C} \times 2 \mathrm{~h}-\mathrm{AC}, 870^{\circ} \mathrm{C} \times 4 \mathrm{~h}-\mathrm{AC}$ \\
M252 & $\mathrm{G}$ & $1065^{\circ} \mathrm{C} \times 8 \mathrm{~h}-\mathrm{AC}, 760^{\circ} \mathrm{C} \times 15 \mathrm{~h}-\mathrm{AC}$ \\
\hline
\end{tabular}


12 Nimonic $80 \mathrm{~A}$ Nimonic 90 は高 い鞓性を老。 M252 は多量の Mo 弆台むが，C 量が高く $r^{\prime}$ 相を 析出せ放ため高 温に打け方䩖性の 低下は少ない。ま たAl含有晃の高 いInco $73{ }^{\circ}$, Inco 700 杉よび $\mathrm{Nb}$ 范含吉 Inconel X-550 いい゙れも $\gamma^{\prime}$ 相の析出が多 いた﨡性は低 い. とくに Inco 700 汢試娩温度 $750^{\circ} \mathrm{C}$ より $800^{\circ} \mathrm{C}$ となつても鞄性は 低下していること 法, $800^{\circ} \mathrm{C}$ てもな 方门十析出の影 響が他の軟化より 大きれたのと考えられ，他の合金が高温となれば䩒性が 向上していらのと封比される.

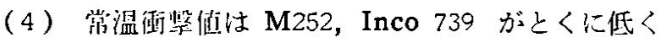
Inconel X-550 はこれにつぎ, Nimonic 80 A, Nimonic 90, Inco 700 が最も高い.

寸なおち $\mathrm{Mo}, \mathrm{Al}, \mathrm{Nb}$ 含有量が高くなれば徒揧値は低 下するが，Inco 700 のごとくCo 含有量が高くなれば Moを含んでもその量が少ないので衝慗值の低下は緩和 される. Inco 739 は裳温引張試験の伸び，絞りは高い が，徆整値のみ低い点は他の合金と異つている.

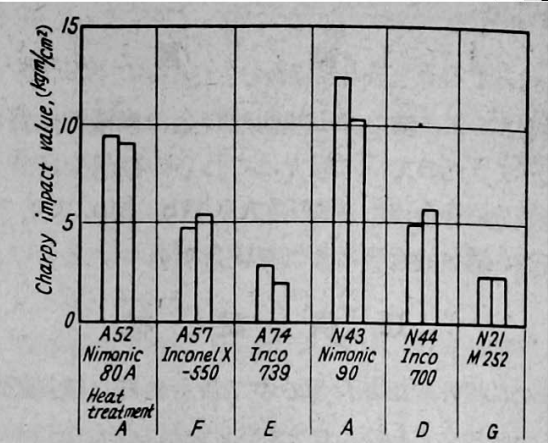

Fig. 2. Charpy impact value of various Ni-base heat-resisting alloys.

\section{IV. クリープ破断試験結果}

Fig. 3，4 に 750 および $816^{\circ} \mathrm{C}$ におけるクリーナ披 断応力一時間関係を示し，Table 3 にこれらにより求め たクリープ破断応力を表示する.これらの結果および短

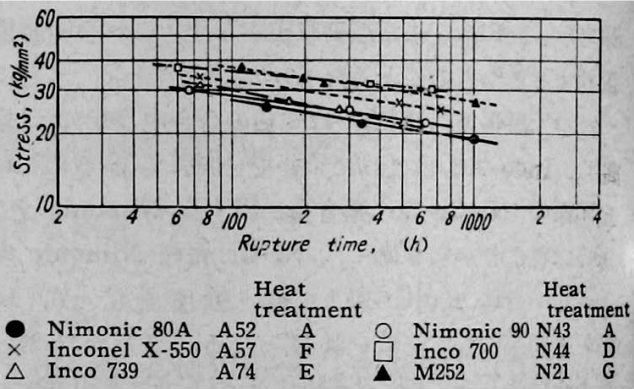

Fig. 3. Stress rupture strength at $750^{\circ} \mathrm{C}$.

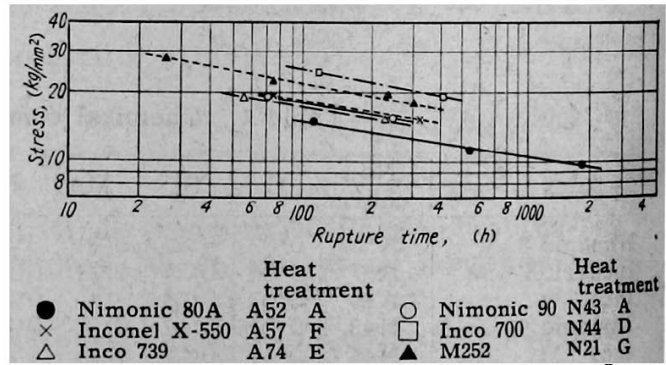

Fig. 4. Stress rupture strength at $816^{\circ} \mathrm{C}$ :

Table 3. Stress rupture strength at 750 and $816^{\circ} \mathrm{C}$ of various $\mathrm{Ni}$-base heat-resisting alloys $\left(\mathrm{kg} / \mathrm{mm}^{2}\right)$

\begin{tabular}{|c|c|c|c|c|c|c|}
\hline \multirow{2}{*}{ Alloy } & \multirow{2}{*}{ No. charge } & \multicolumn{3}{|c|}{$750^{\circ} \mathrm{C}$} & \multicolumn{2}{|c|}{$816^{\circ} \mathrm{C}$} \\
\hline & & $100 \mathrm{~h}$ & $300 \mathrm{~h}$ & $1000 \mathrm{~h}$ & $100 \mathrm{~h}$ & $300 \mathrm{~h}$ \\
\hline $\begin{array}{l}\text { Nimonic } 80 \mathrm{~A} \\
\text { Inconel X-550 } \\
\text { Inco } 739 \\
\text { Nimonic } 90 \\
\text { Inco } 700 \\
\text { M } 252\end{array}$ & $\begin{array}{l}\text { A } 52 \\
\text { A } 57 \\
\text { A } 74 \\
\text { N43 } \\
\text { N44 } \\
\text { N21 }\end{array}$ & $\begin{array}{l}28 \cdot 0 \\
32 \cdot 5 \\
30 \cdot 0 \\
29 \cdot 0 \\
36 \cdot 0 \\
37 \cdot 0\end{array}$ & $\begin{array}{l}23 \cdot 0 \\
28 \cdot 0 \\
24 \cdot 8 \\
25 \cdot 0 \\
32 \cdot 5 \\
32 \cdot 0\end{array}$ & $\begin{array}{l}19 \cdot 0 \\
24 \cdot 0 \\
20 \cdot 3 \\
20 \cdot 5 \\
29 \cdot 0 \\
27 \cdot 0\end{array}$ & $\begin{array}{l}14 \cdot 5 \\
18 \cdot 2 \\
17 \cdot 2 \\
18 \cdot 0 \\
24 \cdot 8 \\
21 \cdot 8\end{array}$ & $\begin{array}{l}12 \cdot 5 \\
15 \cdot 2 \\
14 \cdot 3 \\
14 \cdot 5 \\
20 \cdot 0 \\
18 \cdot 0\end{array}$ \\
\hline
\end{tabular}


Table 4. Stress rupture strength calculated by master rupture curves $\left(\mathrm{kg} / \mathrm{mm}^{2}\right)$

\begin{tabular}{|c|c|c|c|c|c|c|c|}
\hline Temperature & $\underset{h}{\text { Time }}$ & $\begin{array}{c}\text { Nimonic } \\
80 \text { A } \\
\text { A53 }\end{array}$ & $\begin{array}{c}\text { Inconel } \\
\text { X-555 } \\
\text { A57 }\end{array}$ & $\begin{array}{l}\text { Inco } \\
739 \\
\text { A 74 }\end{array}$ & $\begin{array}{c}\text { Nimonic } \\
90 \\
\text { N43 }\end{array}$ & $\begin{array}{c}\text { Inco } 700 \\
\text { N44 }\end{array}$ & $\begin{array}{c}\text { M } 252 \\
\text { N21 }\end{array}$ \\
\hline 600 & $\begin{array}{r}10 \\
100 \\
1000\end{array}$ & $\frac{\overline{-}}{59 \cdot 0}$ & $\overline{55 \cdot 0}$ & $\overline{65 \cdot 0}$ & $\frac{-}{63 \cdot 0}$ & $\frac{-}{73 \cdot 0}$ & $\frac{-}{79 \cdot 0}$ \\
\hline 650 & $\begin{array}{r}10 \\
100 \\
1000\end{array}$ & $\begin{array}{r}-\overline{56.0} \\
44.0\end{array}$ & $\begin{array}{l}- \\
53 \cdot 0 \\
45 \cdot 0\end{array}$ & $\begin{array}{l}-\overline{62 \cdot 0} \\
48 \cdot 0\end{array}$ & $\begin{array}{l}-\overline{61 \cdot 0} \\
47 \cdot 0\end{array}$ & $\begin{array}{l}\frac{1}{69 \cdot 0} \\
55 \cdot 0\end{array}$ & $\begin{array}{l}76 \cdot 0 \\
60 \cdot 0\end{array}$ \\
\hline$\therefore 700$ & $\begin{array}{r}10 \\
100 \\
1000\end{array}$ & $\begin{array}{l}54 \cdot 0 \\
41 \cdot 0 \\
29 \cdot 5\end{array}$ & $\begin{array}{l}52 \cdot 0 \\
43 \cdot 0 \\
34 \cdot 0\end{array}$ & $\begin{array}{l}60 \cdot 0 \\
45 \cdot 0 \\
31 \cdot 0\end{array}$ & $\begin{array}{l}59^{\circ} 0 \\
43 \cdot 0 \\
31^{\circ} 0\end{array}$ & $\begin{array}{l}67^{\circ} 0 \\
53^{\circ} 0 \\
40^{\circ} 0\end{array}$ & $\begin{array}{l}73 \cdot 0 \\
58 \cdot 0 \\
41 \cdot 0\end{array}$ \\
\hline 750 & $\begin{array}{r}10 \\
100 \\
1000\end{array}$ & $\begin{array}{l}40.0 \\
28 \cdot 0 \\
19 \cdot 0\end{array}$ & $\begin{array}{l}42 \cdot 0 \\
32 \cdot 5 \\
23 \cdot 5\end{array}$ & $\begin{array}{l}44 \cdot 0 \\
30^{\cdot} 0 \\
20^{\circ} 0\end{array}$ & $\begin{array}{l}42 \cdot 0 \\
29 \cdot 5 \\
20 \cdot 5\end{array}$ & $\begin{array}{l}52 \cdot 0 \\
38 \cdot 5 \\
28 \cdot 0\end{array}$ & $\begin{array}{l}56^{\circ} \mathrm{O} \\
39 \cdot \mathrm{C} \\
26 \cdot 0\end{array}$ \\
\hline 800 & $\begin{array}{r}10 \\
100 \\
1000\end{array}$ & $\begin{array}{l}27 \cdot 5 \\
18 \cdot 0 \\
12 \cdot 0\end{array}$ & $\begin{array}{l}32 \cdot 0 \\
23 \cdot 0 \\
14 \cdot 0\end{array}$ & $\begin{array}{l}29 \cdot 5 \\
19 \cdot 5 \\
13 \cdot 0\end{array}$ & $\begin{array}{l}29 \cdot 0 \\
20 \cdot 0 \\
13 \cdot 5\end{array}$ & $\begin{array}{l}38 \cdot 0 \\
27 \cdot 5 \\
18 \cdot 5\end{array}$ & $\begin{array}{l}38 \cdot 0 \\
25 \cdot 0 \\
16 \cdot 5\end{array}$ \\
\hline 850 & $\begin{array}{r}10 \\
100 \\
1000\end{array}$ & $\begin{array}{c}18 \cdot 0 \\
11 \cdot 7 \\
-\end{array}$ & $\begin{array}{c}23 \cdot \mathrm{C} \\
13 \cdot 5 \\
-\end{array}$ & $\begin{array}{l}19 \cdot 5 \\
13 \cdot 0 \\
-\end{array}$ & $\begin{array}{c}20 \cdot 0 \\
13 \cdot 5 \\
-\end{array}$ & $\begin{array}{l}27 \cdot 5 \\
18 \cdot 2 \\
-\end{array}$ & $\begin{array}{c}25 \cdot 5 \\
16 \cdot 0 \\
-\end{array}$ \\
\hline 900 & $\begin{array}{r}10 \\
100 \\
1000\end{array}$ & $\begin{array}{l}12 \cdot 2 \\
-\end{array}$ & $\begin{array}{c}14 \cdot 5 \\
-\end{array}$ & $\begin{array}{c}13 \cdot 5 \\
-\end{array}$ & $\frac{13 \cdot 8}{-}$ & $\begin{array}{c}18 \cdot 8 \\
-\end{array}$ & $\begin{array}{c}16 \cdot 5 \\
-\end{array}$ \\
\hline
\end{tabular}

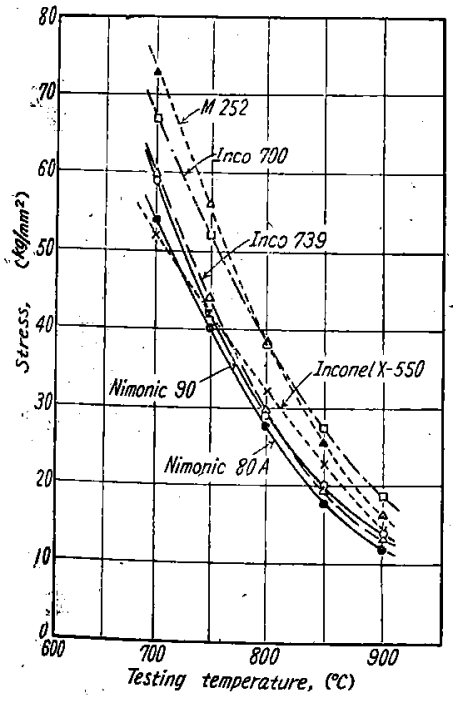

Fig. 5. 10 hours stress rupture strength.

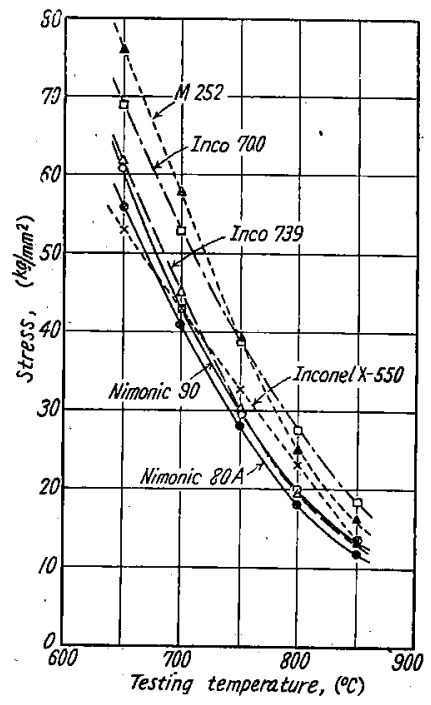

Fig. 6. 100 hours stress rupture strength.

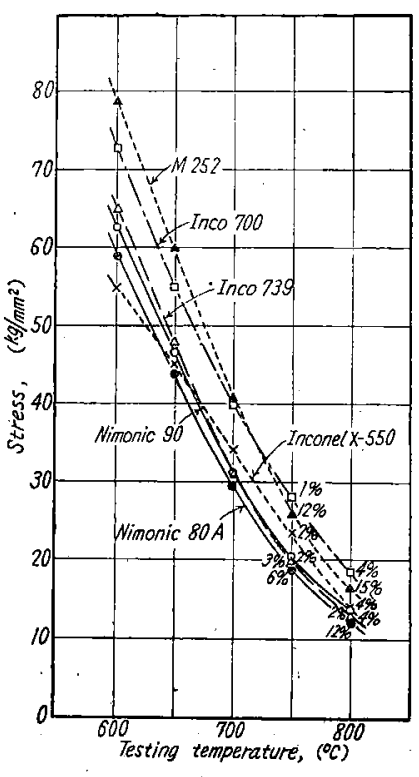

Fig. 7. 1000 hours stress rupture strength.

時間引張試験結果を総合して Larson \& Miller ${ }^{1)} の \quad{ }^{\circ} \mathrm{C}$ の間のクリープ破断応力を求めたのが Table 4 こ， Master Rupture Curve をえがきこれより 600〜900

Fig. 5，6，7 はとの結果よりクリープ破断応力一温度 
関係をえがいたものである.これらの結果より各合金の クリープ破断特性を比較すればつぎのごとくなる.

(1) Ni-Cr-Co 系では Mo 含有量の最も多いM252 は $700^{\circ} \mathrm{C}$ 以下では最む高いクリープ破断応力を示すが， 高温または長時間では Mo 量は少ないが Ti，A1 含有 量の多いInco 700 が高い強度となる. すなわち $10 \mathrm{~h}$ および $100 \mathrm{~h}$ の破断強度では $800^{\circ} \mathrm{C}$ 以上, $1000 \mathrm{~h}$ の破 断強度では Inco 700 の強度が M252 より高くなる.

（2） Ni-Cr 系合金で 3\% Mo を含む Inco 739 は Mo を含をぬ Nimonic $80 \AA$ 上り明らかに高い強度を 示す.また Nimonic 90 と比较すれば $100 \mathrm{~h}$ のクリー プ破断応力では $750^{\circ} \mathrm{C}$ 以下, $1000 \mathrm{~h}$ では $700^{\circ} \mathrm{C}$ 以下で より高いクリープ破断応力を示す.すなわち Mo によ り高温強度が高くなることは前項と同様で，比較的長時 間または高温ではその刘果は次第に減少する。

(3) Nimonic $80 \mathrm{~A}$ と Nimonic 90 を比較すると Nimonic 90 のクリープ破断応力は Nimonic 80 A よ り常に高いのは Co の影響によるむのと考党られる.

(4) Inconel X-550 は $10 \mathrm{~h}$ クリープ破断応力で $750^{\circ} \mathrm{C}$ は以上で Nimonic $80 \mathrm{~A}$ および Nimonic 90 よ り高い強度となる．また $100 \mathrm{~h}$ およ゙ $1000 \mathrm{~h}$ クリー プ破断応力では $700^{\circ} \mathrm{C}$ 以上で Nimonic 90 より高くな り, Inco 700 および-M252 についで高い強度をむつて いる. すなわち Nb は短時間試験ではその勃果は昉ら かでなかつたが，高温長時間試験では明らかに強度向上 に有奻である。

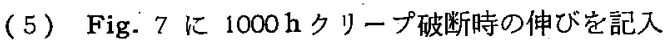
したが Al 含有量多く $\mathrm{Ni}_{3} \mathrm{Al}-\gamma^{\prime}$ を多く析出する Inco 700, Inco 739 打よび Nbを含む Inconel X-550 注 いづれもいちじるしく鞁性が低い。

また $\mathrm{Ni}_{3} \mathrm{Al}$ を活とんど析出しないといわれる M252
は最も高い鞠性を示し，比較的 Al 合有量の低い Nimonic 80A がこれについで勒性が高い。

\section{V. 結論}

6.種の Ni 基耐熱合金の機械的性質を比較し $\mathrm{Mo}, \mathrm{Co}$ $\mathrm{Nb}$ など添加元素の影響ををとめるとつぎのごとくな る.

(1) $\mathrm{Ni}-\mathrm{Cr}$ 系と $\mathrm{Ni}-\mathrm{Cr}-\mathrm{Co}$ 系学比較すると $\mathrm{Co}$ 高温強度の向上に有効であるが，低温または短時間で 明らかでなく，高温または長時間試験で明らかとなる。 またCo は常温および高温の靱性向上に有效であるが， Ti，A1 量が高くなれば Co が多くともクリープ鞠性性 低下する。

(2) Ni-Cr 系，Ni-Cr-Co 系いられれに対してもMo は高温強度の向上に有効であるが，その効果注長時間ま， たは高温度では次第に減少する。したがってMo含有量 の最も多い M252 活 $750^{\circ} \mathrm{C}$ 以下で活最西高い強度を示 すが，これ以上の温度で僦 Ti，Al，Co 量の多いInco 700 が最も高い強度となる. Mo 注常温衝蒤值を低下寸 るが，高温クリープ靶珄を必ずしむ低下せず M252柱6 種の合金中最高のクリープ鞄性を示す。

（3） $\mathrm{Nb}$ は $\mathrm{Ti}, \mathrm{Al}$ と同様に高温強度の向上儿有 効であるが，短時間引張強度では $\mathrm{Nb}$ 岂含まぬ Nimonic $80 \mathrm{~A}$ より低い強度で，クリープ破断試験にてはし めてその効果があらわれ，Ni-Cr 系合金中最む高い強 度を示した．Nbによる政性の低下ははなはだしく，Ti A1 含有量の多い合金と同様に Inconel X-550 のクリ 一プ靶性任低い（昭和３3 年11月寄稿）

$$
\text { 文. 献 }
$$

1) F. R. Larson \& J. Miller: Trans. ASME, Vol. 74 (1952) p.5.5765 776

ドイツの鉄鋼協会から独一英，英一独対訳の鉄銅用語辞典が出ている．乙れは英国の鉄銅協会と 協力して編輯されているが，その企潇の始まりは遠く1936 年ドイッのデュッセルドルフに持ける 上記両学会の連合諈堂大会にさかのぼる.わが国にもこの辞典の初版を母体とした日独英対訳薙敇: 用術語集が出ているが，それと比較するとさすがに長年月家経てるだけに語数惊いちじるしく增加 している. ボケットに入る $10.5 \times 14.5 \mathrm{~cm} 264$ 頁の小型の辞典で，巻末には英，米，独の各種の 単位の換算表も付してある.わが国の本屋のカタログを見ると定価1250 円となっている. 